\title{
Utilization of Stranded Associated Flare Gases for Electricity Generation in Situ Through Gas-to-Wire in the Niger Delta
}

\author{
Anthony Kerunwa, Stanley Toochukwu Ekwueme, Ubanozie Julian Obibuike \\ Department of Petroleum Engineering, School of Engineering and Engineering Technology, Federal University of Technology, Owerr, \\ Nigeria
}

Email address:

anthonykerunwa@rocketmail.com (A. Kerunwa)

\section{To cite this article:}

Anthony Kerunwa, Stanley Toochukwu Ekwueme, Ubanozie Julian Obibuike. Utilization of Stranded Associated Flare Gases for Electricity Generation in Situ Through Gas-to-Wire in the Niger Delta. International Journal of Oil, Gas and Coal Engineering.

Vol. 8, No. 1, 2020, pp. 28-34. doi: 10.11648/j.ogce.20200801.15

Received: February 6, 2020; Accepted: February 19, 2020; Published: February 28, 2020

\begin{abstract}
The large volume of stranded associated gas in the Niger Delta which has sadly been flared holds great prospect in addressing Nigeria's electricity problem if properly harnessed. The predominance of central electricity production system has over the years shown incapability in generating enough electricity needed by the Nigeria populace. Even with the little generated, large losses are seen as they are transmitted from areas of generation to areas of consumption through the national grid system. A new system of electricity system has to be initiated capable of generating electricity even in smaller amounts for a geographical location. This power when generated and utilized insitu will save losses from transmission lines serve areas not previously contacted by the grid system. In this work, gas-to-wire technology is used to convert 5MMscfd of stranded associated flare gas in Ohaji North in the Niger delta to electricity using combine cycle gas turbine. The gas volume was sufficient for the production of $44.2 \mathrm{MW}$ of electricity per day. Economic evaluation of the project gives a Net present value at $10 \%$ discount rate of USD 108150066, the pay-out-time of 2.69 years and a discounted cashflow rate of return of 37 years making the project a highly profitable one recommended for Nigeria as a solution to the poor electricity generation problem.
\end{abstract}

Keywords: Utilization, Stranded Gas, Electricity Production, Gas-to-Wire, Power Generation

\section{Introduction}

Several Researchers who analyzed the problem of underdevelopment in Nigeria have linked it to electricity. Electricity has been the base of measurement of the development of nations. Sadly, Nigeria has failed in its electricity and power sector. Despite the enormous reserves of natural gas, Nigeria has not been able to produce adequate electrical power for its citizens. A peak power of about 6000 MW has been recorded since the history of electricity production in Nigeria, a figure far below the average rule of thumb of $1000 \mathrm{MW}$ for 1 million heads of population. Since the Nigeria population is nearly 200 million, the average peak power produced amounts to only $30 \mathrm{MW}$ per million heads of population.

Natural gas possesses the potential to be used in the production of electricity using gas turbine systems [1]. From this, several power plants utilising natural gas have been built in Nigeria. These includes, Afam Power Plant, Egbin Power Plant etc. These big power plants require large volumes of feed gas supplied by large pipeline systems. In most cases, the gas from several fields are not sufficient in volume to be used as feed gas for big power plants. Aside the volume constraints, the natural gas may be far away from designated power stations making them remote and pipeline construction to transport these resources becomes economically prohibitive. Because of these reasons, these gases remain stranded and in most cases become candidates for flaring. According to Nigeria Gas Flare Commercialization Programme [2], Nigeria flared an estimated 289 billion standard cubic feet of gas in 2016, making her one of the top ten gas flaring nations in the world. Approximately 790 million standard cubic feet per day (MMscfd) of natural gas associated with petroleum production is being flared from 
approximately 180 flare sites within Nigeria's oil and gas fields today.

According to [9] the severe environmental degradation of the ecosystem resulting to loss of ecological lives, emergence of sicknesses, air, water and land pollution, release of poisonous gases that hampers human habitation, release of greenhouse gases resulting to global warming etc. are some of the attendant effects of gas flaring. With all these, the Niger Delta of Nigeria can be said to be the area most impacted by oil activities in the world.

The goal of the world health organization to completely eradicate gas flaring by 2030, has forced many countries to make laws that favour the utilization of associated gas and the further development of gas projects. Many Gas projects exit for the monetisation of stranded associated flare gases. Among these technologies are Gas-to-Liquids, Liquefied natural gas, compressed natural gas, Natural gas Liquids, Gas-to-wire. These technologies provide means for onsite monetisation of the otherwise flared resource [6].

To tackle the Electricity problem in Nigeria, it is important that power generation be decentralized, this means that several outlet will exit for power generation which will alleviate power insufficiency in certain remote areas comparably inaccessible by the national grid system. Gas-towire is the generation of electrical power onsite in the area where the gas is produced [10]. This will exclude the cost of pipeline construction and pipeline sabotage associated with having to transport natural gas to big power plants for electricity production. Gas-to-wire technology provides immediate electricity to host communities and surplus to sold or sent the national grid.

In this research work, a study on the utilization of stranded associated flare gases in the Niger Delta for electricity generation in situ through gas-to-wire technology was carried out. This was necessary to address the electricity challenges in Nigeria as these stranded associated gases are been flared on daily basis. This was achieved through a methodical approach which involves gas capture and treatment, recovery of heavier hydrocarbons and finally the production of electricity via Gas Turbines. The Power usage calculation of the community used as a case study was carried to ascertain the electrical energy requirements of each household of the community. Finally, economic evaluation of the gas-to-wire technology was carried out to ascertain the profitability of the proposed technology.

\section{Theoretical Concept}

We discuss the several gas monetisation technologies and the type of turbine system utilized in the production of electricity using natural gas

\subsection{Gas Monetisation Technologies}

Several gas monetization technologies exist that could be used to extinguish flares in Nigeria. Some of the most promising technologies are briefly discussed below.

\subsubsection{Gas-To-Wire}

Presently, much of natural gas transported is used for electricity generation at the final destination. Through gas-towire, GtW, generation of electricity can be done anywhere, particularly at or near the reservoir source and transported by cable to the required destination (s). For instance, offshore or isolated gas could be used to fuel and offshore power plant which would generate electricity for sale onshore or to other offshore customers. The challenges of GtW includes the high cost of installing power lines, significant energy losses from cables along the distance transmission lines and large volume of gas needed for power generation [8].

This means holds great potentials for a country like Nigeria that is grappling with power supply. The electricity can be generated at the field, close to the field or the gas can be channeled to huge turbine plants for mega electricity generation [12]. The generation of power form electricity at or near the field is termed gas to wire. It is a special case of gas to power that encourages stranded gas utilization and flare gas reduction. The power can be used in power onsite equipment, some of it sent to nearby host communities and depending on the quantity of production others sent to the national grid system.

\subsubsection{Natural Gas Liquids (NGL) Extraction}

Associated gas is composed of methane and natural gas liquids (NGL). NGL is mainly composed of ethane, propane, butane and heavier hydrocarbons. OFG is dissolved in or volatilized from petroleum due to the changing pressure in the presence of crude oil exploration. Recovery of NGL from OFG will upgrade the quality of commodity natural gas while heavier hydrocarbons recovered are of higher value than methane and are sold.

\subsubsection{Liquefied Natural Gas (LNG)}

Liquefied natural gas (LNG) is natural gas that has been cooled to the point that it condenses to a liquid, a transformation occurring at a temperature of approximately $256^{\circ} \mathrm{F}\left(-160^{\circ} \mathrm{C}\right)$ and at atmospheric pressure. The technology is particularly helpful where pipeline transportation is less attractive due to technological or political reasons. Therefore LNG technology makes natural gas available throughout the world. Conventional LNG plants require large feed gas volumes in the range $450-600 \mathrm{MMscfd}$ or $3.8-5.5 \mathrm{mtpa}$ (metric ton per annum) per LNG train. Therefore, substantial investment in upstream gas gathering will be required to develop small gas reserve into onshore LNG. These factors limit the prospects of developing remote stranded gas via conventional LNG [8].

\subsubsection{Compressed Natural Gas (CNG)}

Gas can be transported in containers at high pressures, typically 1800 psig for a rich gas (significant amounts of ethane, propane, etc.) to roughly 3600 psig for a lean gas (mainly methane). Gas at these pressures is termed 'compressed natural gas (CNG).

CNG is a fossil fuel substitute for gasoline (petrol), diesel or propane fuel. This is made by compressing natural gas 
mainly methane to less than $1 \%$ of the volume it occupies at standard atmospheric pressure. It is stored and distributed in hard containers at a pressure of 200-248 bar (2900-3600psi) usually in cylindrical or spherical shapes. It combustion produces gases with lower pollution and greenhouse gases than other conventional fuels [13].

$\mathrm{CNG}$ is used in some countries for vehicular transport as an alternative to conventional fuels (gasoline or diesel). However, the time to fill a tank with 3000 psig gas can be slow and frustrating. The filling stations can be supplied by pipeline gas but the compressors needed to get the gas to 3000 psig. The thermodynamics of gas compression (heat generation), and gas expansion (significant cooling), have to be considered in any gas processing operation and appropriate heat exchangers used, which adds significant costs.

\subsubsection{Natural Gas to Hydrate (NGH)}

The term "gas hydrates" refers to crystalline compounds that are composed of water and any of the following light molecules: methane, ethane, propane, iso-butane, normal butane, nitrogen, carbon dioxide, and hydrogen sulfide. It is known that some polar components between the sizes of argon $(0.35 \mathrm{~nm})$ and ethyl cyclohexane $(0.9-1)$ can also form hydrates. Hydrate formation usually occurs when water molecule exists in the vicinity of these molecules at temperatures above or below the ice point and relatively high pressure. The water molecules enclose these host molecules and form cage-like structures which are stable at these conditions.

Natural gas can be effectively and efficiently stored as gas hydrate. This can be achieved through proper study and understanding of the processes involved to convert the gas to hydrate and the processes required to prevent the hydrate from dissociating. The storage of natural gas as hydrates will require the synthesis of the hydrate and its regasification. This process is beneficial because the density of natural gas hydrates reduces the space requirements for the storage of natural gas. The stored gas can be used in the future and for peak-shaving applications to obtain a higher price for the natural gas as well as to ensure adequate natural gas supplies during periods of peak usage. Peak-shaving application is storing natural gas when natural gas demand is low, then selling the natural gas during periods of high demand. Gas hydrate can be stored at equilibrium conditions with either its saturation temperature or pressure. The main factors that determine the optimum/limiting pressure and temperature are cost and weight of material, i.e. steel needed for hydrate storage vessel. There are basically three approaches to this operation to make it an economical process:

1) The first is the initial formation of large quantity of gas hydrates to avoid high pressure recompression on recycle,

2) In addition, reproducible, rapid conversion of the gas and water to hydrate to reduce the amount of water transported, and

3) Lastly, the transportation of gas hydrates to locations with small amount of refrigeration and dissociation units needed for the whole operation.

\subsubsection{Gas-To-Liquids (GTL)}

GTL is a catalytic process which involves the chemical conversion of natural gas (primarily methane) into liquid hydrocarbons [4]. It is one of the appropriate options in utilization of natural gas. The main products includes naphtha, diesel, gasoline, jet fuels, white oils, waxes, methanol, DME etc. they produce premium quality liquid fuels that burns cleaner than ones gotten from crude oil fractions. GTL technologies can be in large scale or in small scale (mini GTL).

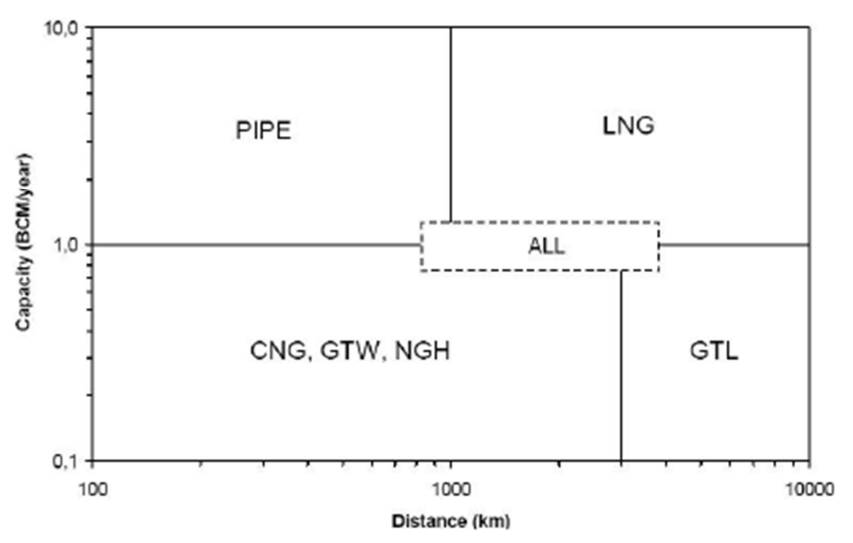

Figure 1. The capacity distance diagram [11].

\subsection{Gas Turbines}

A gas turbine, also called a combustion turbine, is a type of internal combustion engine. It has an upstream rotating compressor coupled to a downstream turbine, and a combustion chamber in between. The gas turbine is the heart of the power plant. A gas turbine is a combustion engine that can convert natural gas or other liquid fuels to mechanical energy which then drives a generator that produces electrical energy or power output.

Gas turbine engines derive their power from burning fuel in a combustion chamber and using the fast flowing combustion gases to drive a turbine in much the same way as the high pressure steam drives a steam turbine. One major difference however is that the gas turbine has a second turbine acting as an air compressor mounted on the same shaft. The air turbine (compressor) range between 30\% and $40 \%$. (The efficiencies of aero engines are in the range $38 \%$ and $42 \%$ while low power microturbines $(<100 \mathrm{~kW})$ achieve only $18 \%$ to $22 \%$ ). Although increasing the firing temperature increases the output power at a given pressure ratio, there is also a sacrifice of efficiency due to the increase in losses due to the cooling air required to maintain draws in air, compresses it and feeds it at high pressure into the combustion chamber increasing the intensity of the burning flame. It is a positive feedback mechanism. As the gas turbine speeds up, it also causes the compressor to speed up forcing more air through the combustion chamber which in turn increases the burn rate of the fuel sending more high pressure hot gases into the gas turbine increasing its speed 
even more. Uncontrolled runaway is prevented by controls on the fuel supply line which limit the amount of fuel fed to the turbine thus limiting its speed.

The thermodynamic process used by the gas turbine is known as the Brayton cycle. Analogous to the Carnot cycle in which the efficiency is maximized by increasing the temperature difference of the working fluid between the input and output of the machine, the Brayton cycle efficiency is maximized by increasing the pressure difference across the machine. The gas turbine is comprised of four main components: a compressor, a combustor, a turbine and a generator. The working fluid, air, is compressed in the compressor (adiabatic compression - no heat gain or loss), then mixed with fuel and burned by the combustor under constant pressure conditions in the combustion chamber (constant pressure heat addition). The resulting hot gas expands through the turbine to perform work (adiabatic expansion). Much of the power produced in the turbine is used to run the compressor and the rest is available to run auxiliary equipment and do useful work. The system is an open system because the air is not reused so that the fourth step in the cycle, cooling the working fluid, is omitted [15].

Gas turbines have a very high power to weight ratio and are lighter and smaller than internal combustion engines of the same power. Though they are mechanically simpler than reciprocating engines, their characteristics of high speed and high temperature operation require high precision components and exotic materials making them more expensive to manufacture [5].

\subsubsection{Turbine Configurations}

Gas turbine power generators are used in two basic configurations.

\section{i. Simple Cycle Turbines}

A gas turbine consumes considerable amounts of power just to drive its compressor. As with all cyclic heat engines, a higher maximum working temperature in the machine means greater efficiency (Carnot's Law), but in a turbine it also means that more energy is lost as waste heat through the hot exhaust gases whose temperatures are typically well over $1,000^{\circ} \mathrm{C}$. Consequently simple cycle turbine efficiencies are quite low. For heavy plant, design efficiencies the turbine components at reasonable working temperatures [14].

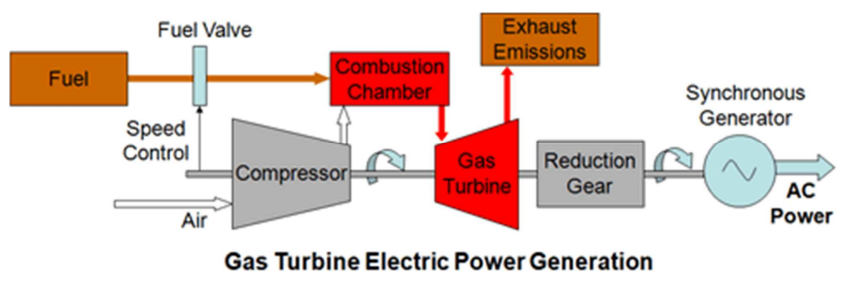

Figure 2. Schematics of simple cycle gas turbine [14].

ii. Combined Cycle Turbines

Are designed for maximum efficiency in which the hot exhaust gases from the gas turbine are used to raise steam to power a steam turbine with both turbines being connected to electricity generators. It is however possible to recover energy from the waste heat of simple cycle systems by using the exhaust gases in a hybrid system to raise steam to drive a steam turbine electricity generating set. In such cases the exhaust temperature may be reduced to as low as $140^{\circ} \mathrm{C}$ enabling efficiencies of up to $60 \%$ to be achieved in combined cycle systems [7]. In combined-cycle applications, pressure ratio increases have a less pronounced effect on the efficiency since most of the improvement comes from increases in the Carnot thermal efficiency resulting from increases in the firing temperature. Thus simple cycle efficiency is achieved with high pressure ratios. Combined cycle efficiency is obtained with more modest pressure ratios and greater firing temperatures.

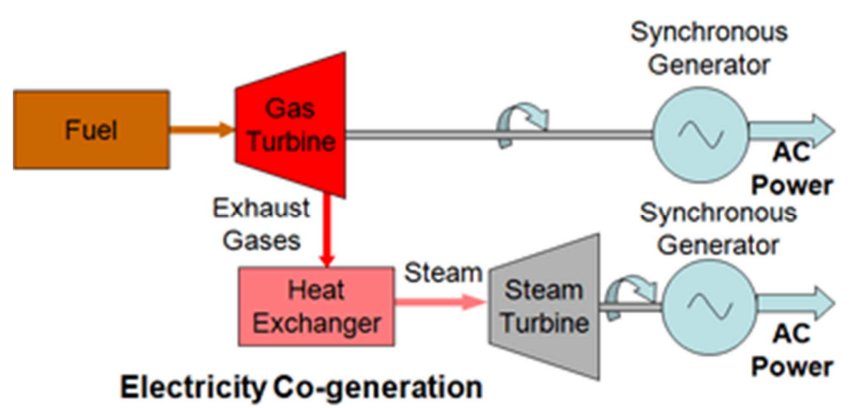

Figure 3. Schematics of combined cycle gas turbine [14].

\subsubsection{Turbine Power Output}

To minimize the size and weight of the turbine for a given output power, the output per pound of airflow should be maximized. This is obtained by maximizing the air flow through the turbine which in turn depends on maximizing the pressure ratio between the air inlet and exhaust outlet. The main factor governing this is the pressure ratio across the compressor which can be as high as 40:1 in modern gas turbines. In simple cycle applications, pressure ratio increases translate into efficiency gains at a given firing temperature, but there is a limit since increasing the pressure ratio means that more energy will be consumed by the compressor [3].

\section{Methodology}

The processes involved in the production of electricity using stranded associated flare gas through gas-to-wire technologies is given below

1. Gas capture and treatment.

2. Recovery of heavier hydrocarbons.

3. Electricity production via Gas Turbines.

\subsection{Gas capture and Treatment}

Flare gas is captured from flare stack system and routed to the gas treatment unit. In the gas treatment unit acid gases are removed from the gas stream. Acid gases comprise $\mathrm{H}_{2} \mathrm{~S}$ and $\mathrm{CO}_{2}$. They have to be removed to avoid damages in terms of corrosion of the processing equipment and metallic parts. 


\subsection{Recovery of Heavier Hydrocarbons}

The component of natural gas needed for electricity production is methane. But natural gas contains other heavier hydrocarbons. These streams must be extracted as natural gas liquids. The extraction method depends on the mole composition of the gas and the downstream use of the resulting feed gas.

\subsection{Electricity Production via Gas Turbine}

The resulting dry gas is sent to the Gas turbine system for electricity production. The gas turbine system used here is the combined cycle gas turbine because of its higher electrical output and efficiency than the single gas turbine system.

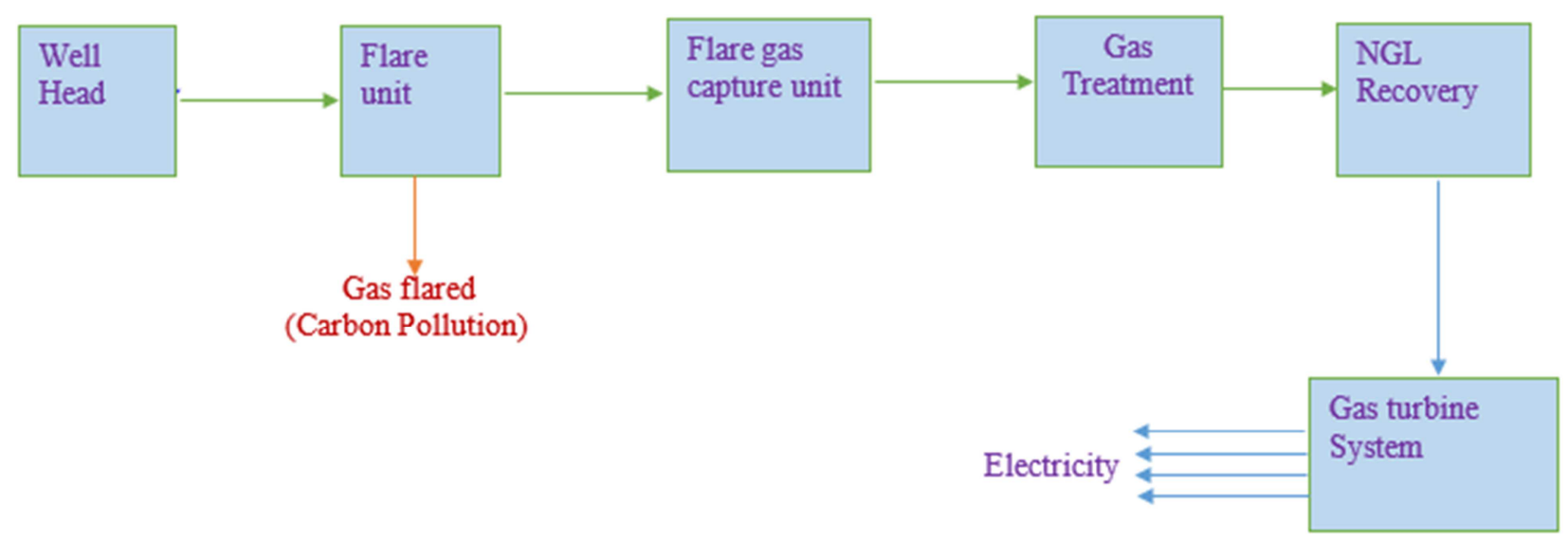

Figure 4. Electricity Production through Combined Cycle Gas Turbine.

\subsubsection{Electricity Generation}

$1 \mathrm{kwh}=3412 \mathrm{Btu}=3.6 \mathrm{MJ}$

Gas turbine efficiency affects heat rate.

$100 \%$ efficient gas turbine will generate $3.6 \mathrm{MJ} / \mathrm{Kwh}=$ $3412 \mathrm{btu} / \mathrm{kWh}$

From table, the calorific value of pure methane is $45 \mathrm{MJ} / \mathrm{kWh}$.

Thus a $100 \%$ efficient gas turbine utilising biomethane with calorific value $45 \mathrm{MJ} / \mathrm{m}^{3}$ will generate $12.5 \mathrm{kWh} / \mathrm{m}^{3}$.

For a combine cycle gas turbine with $60 \%$ efficiency, the methane consumption of the turbine $=12.5 \mathrm{kWh} / \mathrm{m}^{3} \times 0.6$ $=7.5 \mathrm{kWh} / \mathrm{m}^{3}$.

The volume of the gas turbine feed gas is $5 \mathrm{MMscf}$, this is equivalent to $141584.23 \mathrm{~m}^{3}$ of methane gas.

The electrical power to be produced from the CCGT for $566337 \mathrm{~m}^{3}$ volume of methane $=7.5 \mathrm{kWh} \times 141584.23 \mathrm{~m}^{3}=$
$1061881.725 \mathrm{Kwh}$.

Converting to Megawatts we divide by 24000 (i.e. 24 multiplied by 1000). The electrical output of the 5MMscf of gas using $60 \%$ combined cycle gas turbine is $44.2 \mathrm{MW}$. Thus with an average power requirement of $0.3124 \mathrm{Kwh}$, the power generated will be sufficient for 3,399,109 Households.

\subsubsection{Power Usage Calculation}

If the electrical energy generated is to be wholly sold or supplied to host communities, it is pertinent to ascertain the number of households or individuals that the electrical energy will be sufficient to meet. For this reason we calculate the electrical energy requirement of each household. For equipment ratings, check the label of equipment and record their values accordingly, otherwise check with local appliance dealers or product manufacturers for information.

Table 1. Power Ratings for a Typical Rural Home Appliances.

\begin{tabular}{|c|c|c|c|c|c|}
\hline Appliance & Consumption (watts) & Number & Total wattage & hrs./day & Watt-hrs./day \\
\hline Energy bulbs & 10 & 6 & 60 & 8 & 480 \\
\hline DVD & 40 & 3 & 120 & 5 & 600 \\
\hline Television & 50 & 3 & 150 & 6 & 900 \\
\hline Mobile phones & 5 & 4 & 20 & 4 & 80 \\
\hline Ceiling fan & 25 & 8 & 200 & 5 & 1000 \\
\hline Radio cassette player & 8 & 2 & 16 & 4 & 64 \\
\hline
\end{tabular}

From the table above, each household requires an average power requirement of 3124 watt-hr per day.

\section{Economic Evaluation}

The economic evaluation of the gas-to-wire technology is done to ascertain economic appraisal parametres like NPV,
POT, DCF-ROR and P/\$ invested.

The capital expenditure (CAPEX) for the plant is US\$50 million while the operating expenditure is $5 \%$ of the CAPEX. The operating expenditure comprises the feedstock (natural gas cost) and the non-feedstock cost. The price of the power generated when sold is given as US0.08/ $\mathrm{kwh}$. A tax rate of $35 \%$ and 350 days of plant operation for a plant life of 20 years is utilized. 


\section{Result and Discussion}

\subsection{Electricity Generation}

The electrical output of the 5MMscf of gas using $60 \%$ combined cycle gas turbine (CCGT) is $44.2 \mathrm{MW}$. Thus with an average power requirement of $0.3124 \mathrm{Kwh}$, the power generated will be sufficient for 3,399,109 Households since 3124 watt-hr per day of power is the power requirement of each household. Therefore, with this quantity of power generated, the revenue base of Nigeria will be greatly increased, thus converting the flared gas to wealth.

\subsection{Economic Evaluation}

The result for the economic evaluation of the gas-to-power project is given in table 2 below:
Table 2. Table of Profit Indicators of the Gas-to-wire Project.

\begin{tabular}{ll}
\hline Economic Parameter & Value \\
\hline Annual Cashflow/NCR (US\$) & $18,576,247$ \\
NPV @ 10\% Discount Rate (US\$) & 108150066 \\
NPV @ 15\% Discount Rate (US\$) & 66274890 \\
DCF-ROR (\%) & 37 \\
Pay-Out Time, POT (yrs) & 2.69 \\
P/\$ & 6.43 \\
\hline
\end{tabular}

From table 2 above, the NPV of the project at $10 \%$ and $15 \%$ discount rates are US\$108150066 and US\$66274890 respectively, the DCF-ROR is $37 \%$ and the Pay-out time is 2.69 years. The profit per investment ratio is 6.43 . The values show that the project is highly economically viable.

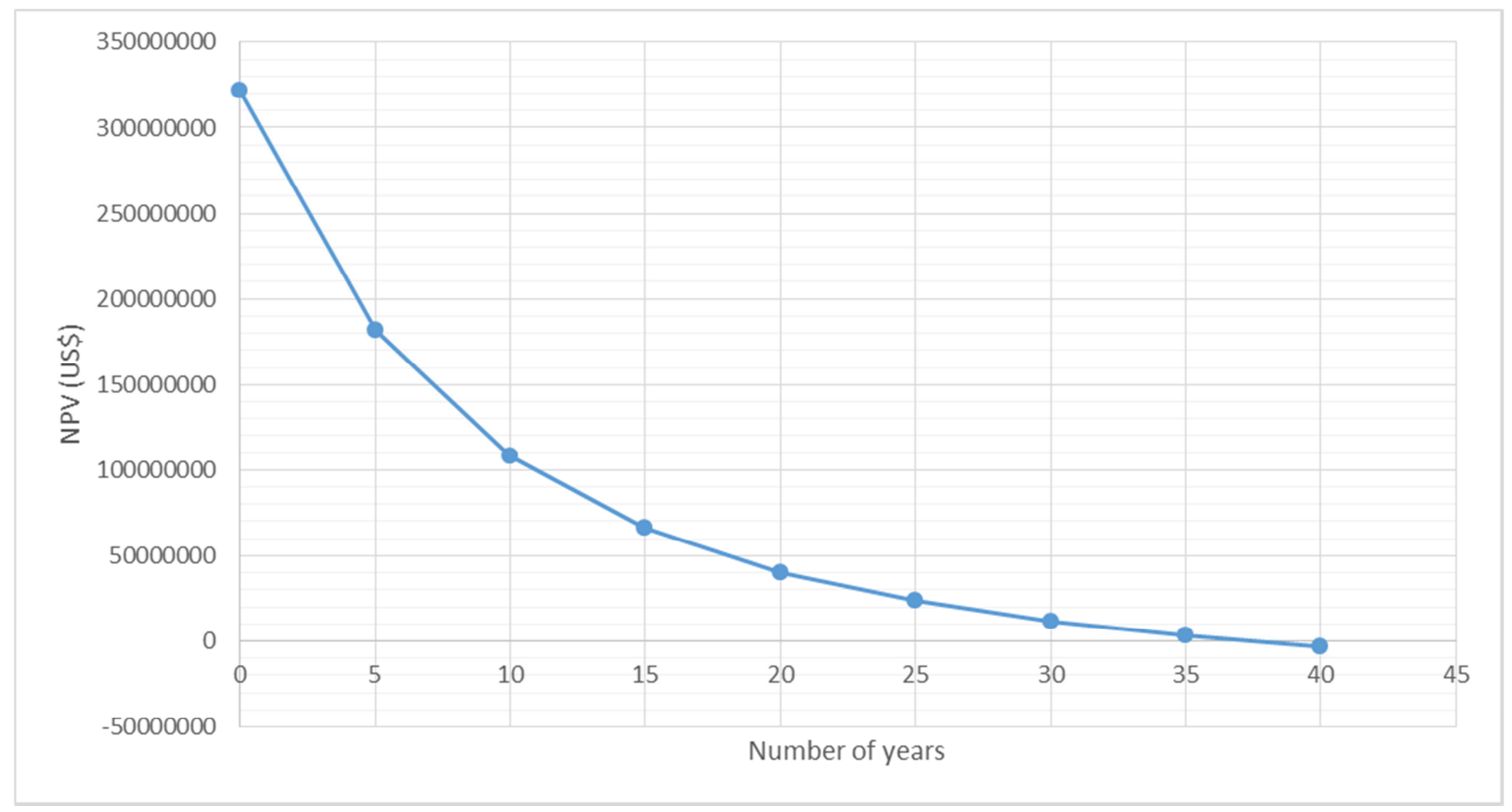

Figure 5. Figure showing the Relationship between the NPV and Discount rates.

From figure 4 above, the curve cut the $\mathrm{x}$-axis at $37 \%$, this point is the DCF-ROR. This means that the project is profitable as long as the discount rate is below $37 \%$.

\section{Conclusion}

Method for utilization of stranded associated flare gas through gas-to-wire in production of onsite electricity has been developed in this work. The method used is combined cycle gas turbine because of its relatively higher efficiency that the single cycle turbine systems. From the 5MMscfd of flare gas utilized for power generation using gas-to-wire technology, 44.2 MW would the be generated. If this electrical power were solely utilized by the host communities in close proximity to the site, then the generated power would be sufficient for 3,399,109 households having an average daily power consumption of $0.3124 \mathrm{Kwh}$. Economic analysis reveals the profitability of the project. The project has a pay-out-time of 2.69 years with a Net present value of USD 108150066 at $10 \%$ discount rate. The Discounted cashflow rate of return (DCFROR) is $37 \%$ while the profit per dollar invested is 6.43 . These economic indices reveals that the project is highly profitable.

Gas-to-wire system of electricity generation will aid in drastic utilization of associated flare gases in the Niger Delta while helping to provide electricity to rural settlements especially areas not contacted by the national grid system. The government should bring incentives towards encouraging private investor in the power sector through gasto-wire system. 


\section{References}

[1] Izuwa, N. C. (2017). Improving Natural Gas Distribution and Management in Nigeria. International Journal of Scientific \&Engineering Research, Vol. 8, Issue 2. Pp. 330-344

[2] Nigeria Gas Flare Commercialization Programme. (2018). Request for Qualification. Nigeria: Ministry of Petroleum and natural resources, Nigeria.

[3] Basha M., Shaahid S. M., and Al-Hadhrami L. (2012). Impact of fuels on performance and efficiency of gas turbine power plants. Energy Procedia 14: 558-565.

[4] Chabrelie M. F. and Rojey A. (2010). Prospects for Exploiting Stranded Gas Reserves. Eurogas 2010proceedings, pp 229239.

[5] Chuang C. and Deng-Chern Sue. (2005). Performance effects of combined cycle power plant with variable condenser pressure and loading. Energy 30, no. 10. Pp. 1793-1801.

[6] Global Gas flaring Reduction Partnership (2018). GGFR Technology Overview - Utilization of Small-Scale Associated Gas.

[7] Ibrahim T. K., Basrawi F., Awad O. I., Abdullah A. N., Najafi G., Mamat R., and Hagos F. Y. (2017). Thermal performance of gas turbine power plant based on exergy analysis. Applied thermal engineering 115: 977-985.

[8] Kanshio S. and Ogogo, H. O. (2017). Techno-Economic Assessment of Mini-GTL Technologies for Flare Gas Monetization in Nigeria. Paper Presented at the NAICE SPE, Lagos.
[9] Ojijiagwo, E., Oduoza, C. and Emekwuru, N. (2016). Economics of gas to wire technology applied ingas flare management. UK: Elsevier.

[10] Onwuka, E. I, Iledare, O. O. and Echendu, J. C (2016). Gasto-Power in Nigeria: The burden on Natural gas. Paper presented at the SPE Nigeria annual international conference and exhibition Lagos, Nigeria.

[11] Onwukwe, S. I. and Duru, U. I. (2015): Prospect of Harnessing Associated Gas through Natural gashydrate (NGH) Technology in Nigeria, Journal of Petroleum and Gas Engineering, vol (6) 3, pp. 34-45.

[12] Osaghae E. O, Khan J. A, Roa, J. J. (2004). Gas field monetisation: Major investment Drivers for Gasto Power ventures, Paper prepared for presentation at the SPE Asia Pacific Oil and Gas conference and exhibition held in Perth Australia.

[13] Osokogwu, U., Ademujimi, M., Ajienka, J. A. (2011). Economic Analysis of GTP, GTL, CNG, NGHfor Offshore Gas Development in Nigeria. Paper Presented at the NAICE SPE, Abuja.

[14] Rahman, M. M., IbrahimT. K., and Abdalla A. N.(2011) "Thermodynamic performance analysis of gas-turbine powerplant. International Journal of Physical Sciences 6, no. 14 3539-3550.

[15] Sanjay, Y. (2011). Investigation of effect of variation of cycle parameters on thermodynamic performance of gas-steam combined cycle." Energy 36, no. 1: 157-167. 